\title{
The cholesterol-hydroxyecdysone-vitellogenin pathway is involved in the longevity of trophocytes and oenocytes of queen honey bees (Apis mellifera)
}

\author{
Cheng-Yen Lu' ${ }^{2}$, Po-Jung HuAng ${ }^{1,2,3}$, Chin-Yuan $\mathrm{Hsu}^{1,2,4}$ \\ ${ }^{1}$ Department of Biomedical Sciences, Chang Gung University, 259, Wen-Hwa 1st Road, Kwei-Shan, Tao-Yuan 333, \\ Taiwan \\ ${ }^{2}$ Graduate Institute of Biomedical Sciences, College of Medicine, Chang Gung University, Tao-Yuan, Taiwan \\ ${ }^{3}$ Genomic Medicine Research Core Laboratory, Chang Gung Memorial Hospital, Linkou, Taiwan \\ ${ }^{4}$ Department of Obstetrics and Gynecology, Chang Gung Memorial Hospital, Linkou, Taiwan
}

Received 30 January 2018 - Revised 15 June 2018 - Accepted 23 July 2018

\begin{abstract}
Trophocytes and oenocytes in the abdomen of honey bees do not divide after eclosion; however, trophocytes and oenocytes of queen bees have a longer lifespan and maintain better cellular function than those of worker bees. To explore this phenomenon, we assayed the molecules involved in the cholesterol-hydroxyecdysonevitellogenin $(\mathrm{Vg})$ pathway in the trophocytes and oenocytes of young and old worker and queen bees. The results showed that Vg and cholesterol levels in hemolymph and cholesterol levels, 20-hydroxyecdysone (20E) levels, and the messenger RNA levels of cytochrome P450 314A1 20-hydroxylase (Cyp314A1), ecdysone receptor isoform A (EcR-A), ecdysone receptor isoform B1 (EcR-B1), ultraspiracle (USP), ecdysone-induced protein 74 (E74), ecdysone-induced protein 75 (E75), broad-complex $(B R-C), V g$, and $V g$ receptor $(V g R)$ in trophocytes and oenocytes were increased in queen bees compared with worker bees. These findings indicated that queen bees have higher expression of molecules in the cholesterol-hydroxyecdysone-Vg pathway than worker bees.
\end{abstract}

cholesterol / 20-hydroxyecdysone / vitellogenin / longevity / honey bee

\section{INTRODUCTION}

Queen and worker honey bees are females, however, queen bees can live up to 3 years or 30 times longer than worker bees, which have an average lifespan of 35 days (Remolina \& Hughes, 2008). Thus, queen bees have a much longer lifespan than worker bees, although they share the same genome. Therefore, honey bee (Apis mellifera) is a model animal for studies of

Electronic supplementary material The online version of this article (https://doi.org/10.1007/s13592-018-0596-9) contains supplementary material, which is available to authorized users.

Corresponding author: C. Hsu, hsu@mail.cgu.edu.tw

Manuscript editor: Klaus Hartfelder aging and longevity (Keller \& Jemielity, 2006). In addition, they live in large colonies and are easily manipulated, and their genome has been sequenced and is similar to vertebrate genomes. Genome sequence of honey bees is $47.5 \%$ similar to that of human beings (The Honeybee Genome Sequencing Consortium, 2006; Wang et al., 2006; Elsik et al., 2014).

The longevity of individuals depends on the longevity of their cells. In addition, trophocytes and oenocytes of honey bees are immersed in hemolymph and can be used to test anti-aging drugs when drugs are microinjected into the hemolymph. Therefore, trophocytes and oenocytes are chosen for cellular senescence and longevity studies (Hsieh and Hsu, 2011a). Furthermore, trophocytes and oenocytes are used in cellular senescence and longevity studies due to their 
analogous biological functions as white adipose and liver cells, ease of isolation from the abdomen, and convenient manipulation (Chan et al., 2011; Nilsen et al., 2011; Seehuus et al., 2013). Most importantly, these cells do not divide after eclosion, a necessary requirement for studying aging and longevity (Hsieh and Hsu 2011a, b). Trophocytes and oenocytes of honey bees are located in the abdomen and tightly attach to each other with gap junctions to construct a single layer of cells around each abdominal segment (Kuterbach and Walcott, 1986). Trophocytes are large and irregularly shaped, and oenocytes are small and spherical (Hsieh and Hsu 2011a, b; Paes-de-Oliveira and Cruz-Landim 2003).

Recent studies have shown that cellular functions including mitochondrial energy utilization, energy regulation activity, cellular degradation activity, and cellular metabolism in the trophocytes and oenocytes of worker bees decrease with age (Chuang and Hsu 2013; Hsu and Chuang 2014; Hsu et al. 2014; Lu et al. 2017). However, these processes are maintained with age in queen bees (Hsu and $\mathrm{Hu}$ 2014; Hsu and $\mathrm{Lu} 2015$; Hsu et al. 2016). These findings indicate that the trophocytes and oenocytes of worker bees exhibit aging phenotypes and that those of queen bees show longevity phenotypes, as these cells do not proliferate after eclosion in either worker or queen bees (Hsieh and Hsu 2011a, b). Thus, the longevity of these cells is associated with that of queen bees. Exploring the longevity mechanism of trophocytes and oenocytes can promote the understanding of longevity mechanism of queen bees.

Vitellogenin $(\mathrm{Vg})$, a precursor of yolk protein, is synthesized in the abdominal fat body (Sappington and Raikhel 1995) and is highly expressed in queen and long-lived winter worker bees (Seehuus et al. 2006; Corona et al. 2007; Aurori et al. 2014). Knockdown of Vg decreases the lifespan of worker bees (Nelson et al. 2007). These findings suggest that Vg may be related to the longevity of queen bees in addition to the deposition of yolk in developing oocytes. The transcription of $\mathrm{Vg}$ is regulated by the transcription factors including ecdysone-induced protein 74 (E74), ecdysone-induced protein 75 (E75), and broad-complex (BR-C) (Sun et al. 2002; Yang et al. 2014) and by the ecdysone receptor
(EcR)/ultraspiracle (USP)/20-hydroxyecdysone (20E) nuclear receptor complex (Paul et al. 2005). The nuclear EcR/USP complex functions as the 20E receptor (Hill et al. 2013; Hansen et al. 2014; Mello et al. 2014). 20E, an active ecdysteroid, is synthesized from ecdysone by cytochrome P450 314A1 20-hydroxylase (Cyp314A1). Ecdysone is synthesized from cholesterol in the ecdysteroid biosynthesis pathway (Petryk et al. 2003; Yamazaki et al. 2011). Thus, the cholesterol-hydroxyecdysone-Vg pathway seems to be potentially involved in the longevity of queen bees. However, it remains unclear whether the cholesterol-hydroxyecdysone-Vg pathway is active in the trophocytes and oenocytes of worker and queen bees and whether this pathway is related to the longevity of trophocytes and oenocytes of queen bees.

\section{MATERIALS AND METHODS}

\subsection{Honey bees}

Young (5-day-old) and old (30-day-old) worker bees and young (2-month-old) and old (16month-old) queen bees were collected on the same dates for the same experiments. The breeding and collection of bees were described in our previous studies (Hsu and Chan 2013; Hsieh and Hsu 2013).

\subsection{Hemolymph collection}

Hemolymph was collected from two young or two old worker bees and from one young or one old queen bee between the second and third abdominal segments by capillary tubes (1-000-0500; Drummond Scientific Company, PA, USA). Hemolymph from two worker bees was combined for each sample.

\subsection{Vg levels in hemolymph}

Four microliters of hemolymph (described in Section 2.2) were mixed with $10.5 \mu$ l of the luciferase culture cell lysis reagent, $0.5 \mu \mathrm{l}$ of protease inhibitor (11697498001; Roche Applied Science, IN, USA), and $5 \mu$ of SDS sample buffer. The mixture was centrifuged and resolved on a $10 \%$ 
SDS gel. The gel was stained using Coomassie blue. $\mathrm{Vg}$ is $180 \mathrm{kDa}$ protein (Wheeler and Kawooya, 1990). Five replicates were performed: five samples containing hemolymph from two young and old worker bees and five samples containing the hemolymph of individual young and old queen bees.

\subsection{Cholesterol levels in hemolymph}

Cholesterol levels were quantified using a cholesterol quantitation kit (MAK043; Sigma, MO, USA). Briefly, $1 \mu$ l of hemolymph (described in Section 2.2) was mixed with $200 \mu$ l chloroform/ isopropanol/IGEPAL CA-630 (7:11:0.1) and centrifuged at $13,000 \mathrm{~g}$. The organic phase was transferred to a new tube and dried at $50{ }^{\circ} \mathrm{C}$. Then, the pellet was dissolved in $200 \mu \mathrm{l}$ cholesterol assay buffer to obtain the supernatant. After background luminescence was recorded, $50 \mu \mathrm{l}$ of a diluted standard cholesterol solution $(0,20,40,60,80$, and $100 \mathrm{ng}^{-1} \mathrm{l}^{-1}$ ) or $50 \mu \mathrm{l}$ supernatant were mixed with $44 \mu \mathrm{l}$ cholesterol assay buffer, $2 \mu \mathrm{l}$ cholesterol probe, $2 \mu \mathrm{l}$ cholesterol enzyme mix, and $2 \mu \mathrm{l}$ cholesterol esterase and incubated for $60 \mathrm{~min}$ at $37{ }^{\circ} \mathrm{C}$ in the dark. The cholesterol levels were measured at $570 \mathrm{~nm}$ using a spectrophotometer (Synergy HT; BioTek, VT, USA) and are expressed as nanograms per microliter. A calibration curve using cholesterol standards was used to quantify cholesterol levels. Five replicates were performed: five samples containing hemolymph from two young and old worker bees and five samples containing the hemolymph of individual young and old queen bees.

\subsection{Cholesterol levels in trophocytes and oenocytes}

The assay of cholesterol levels in trophocytes and oenocytes was modified from Section 2.4. Briefly, $10 \mathrm{mg}$ of trophocytes and oenocytes from two young or two old worker bees and one young or one old queen bee were detached from the cuticle of the abdomen using a knife, homogenized with $200 \mu \mathrm{l}$ chloroform/isopropanol/ IGEPAL CA-630 (7:11:0.1), and centrifuged at $13,000 \mathrm{~g}$. The remaining method is the same as Section 2.4. Five replicates were performed: five samples containing supernatant from two young and old worker bees and five samples containing the supernatant of individual young and old queen bees.

\section{6. $20 \mathrm{E}$ levels in trophocytes and oenocytes}

$20 \mathrm{E}$ levels were measured using a 20E enzyme immunoassay kit (A05120; Bertin Pharma, MLB, France). Briefly, $10 \mathrm{mg}$ of trophocytes and oenocytes from two young or two old worker bees and one young or one old queen bee was detached from the cuticle of the abdomen using a knife, homogenized with $400 \mu \mathrm{l}$ of methanol, and centrifuged at $5000 \mathrm{~g}$. Supernatants were transferred into a new tube, dried, and re-dissolved in $200 \mu \mathrm{l}$ of EIA buffer. The 96-well plate was pre-washed with wash buffer, after which $50 \mu$ of a diluted 20E standard solution $(0,39.1,78.1,156.3,312.5$, $625,1250,2500$, and $5000 \mathrm{pg} \mathrm{ml}^{-1}$ ), and $50 \mu \mathrm{l}$ each of samples was loaded onto the plate in duplicate. The plate is incubated at $4{ }^{\circ} \mathrm{C}$ overnight, then emptied and washed with $300 \mu$ wash buffer. Finally, the plate was developed with $200 \mu$ of Ellman's reagent and incubated in the dark at room temperature on a shaker. $20 \mathrm{E}$ levels were measured at $410 \mathrm{~nm}$ using a spectrophotometer (Synergy HT; BioTek) and are expressed as picograms per milliliter. A calibration curve using $20 \mathrm{E}$ standards was used to quantify $20 \mathrm{E}$ levels. Five replicates were performed: five samples containing supernatant from two young and old worker bees and five samples containing the supernatant of individual young and old queen bees.

\subsection{Quantitative real-time polymerase chain reaction analysis}

Trophocytes and oenocytes were isolated from two young or two old worker bees and from one young or one old queen bee. Total RNA was extracted from these cells using TRIzol ${ }^{\circledR}$ Reagent (15596018; Invitrogen, CA, USA). RNA concentration and quality were determined using a Synergy $^{\text {TM }}$ HT multi-mode microplate reader (7091000; BioTek). Complementary DNA (cDNA) synthesis was performed using an iScript $^{\mathrm{TM}}$ cDNA synthesis kit (170-8891; BioRad Laboratories, CA, USA). Each reaction 
contained $1 \mu \mathrm{g}$ of total RNA in a $20 \mu \mathrm{l}$ reaction volume. Quantitative real-time polymerase chain reaction (qPCR) was performed using a CFX connect RT-PCR detection system (Bio-Rad Laboratories), and each reaction contained $0.5 \mu \mathrm{l}$ of $10 \mu \mathrm{M}$ of each primer, $12.5 \mu \mathrm{l}$ of SYBR Green (170-8882; Bio-Rad Laboratories), $1 \mu$ of diluted cDNA, and $10.5 \mu \mathrm{l}$ of $\mathrm{ddH}_{2} \mathrm{O}$ in a final volume of $25 \mu$ l. Primer sequences were shown in supplemental Table S1. The actin gene was used as a reference gene (Lourenco et al., 2008). Five replicates were performed: five samples containing total RNA from two young and old worker bees and five samples containing the total RNA of individual young and old queen bees.

\subsection{Statistical analysis}

Differences in the mean values among the four groups were determined by the Kruskal-Wallis test and followed by the Mann-Whitney $U$ test for pairwise comparisons. The $P$ value less than 0.01 was considered statistically significant.

\section{RESULTS}

\subsection{Vg and cholesterol levels in hemolymph}

To discover molecules associated with the cellular function of trophocytes and oenocytes, we assayed the proteins in hemolymph. The results showed that $\mathrm{Vg}$ concentration in the hemolymph of queen bees was significantly higher than worker bees (Fig. 1a). The fold changes in the mean Vg concentration in hemolymph in old worker bees, young queen bees, and old queen bees relative to young worker bees were $1.36 \pm 0.38$, $21.71 \pm 5.90$, and $24.08 \pm 5.44$, respectively. $\mathrm{Vg}$ levels significantly differed between young worker bees and young and old queen bees and between old worker bees and young and old queen bees ( $n=5, P=0.008$; Fig. 1b).

We propose here a hypothetical cholesterolhydroxyecdysone-Vg pathway as underlying differential longevity in honey bees. In this pathway, dietary cholesterol would be the driver and $\mathrm{Vg}$ production by fat body trophocytes and oenocytes would be the final outcome. To confirm Vg levels, we assayed cholesterol levels in hemolymph because cholesterol is related to $\mathrm{Vg}$ synthesis in the cholesterol-hydroxyecdysone- $\mathrm{Vg}$ pathway. The mean cholesterol levels in the hemolymph of young and old worker bees and young and old queen bees were $299.37 \pm 29.70$, $181.95 \pm 41.61,692.38 \pm 111.16$, and

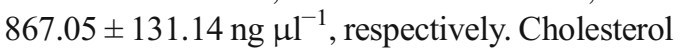
levels significantly differed between young worker bees and young and old queen bees and between old worker bees and young and old queen bees ( $n=5, P=0.008$; Fig. $1 \mathrm{c}$ ). These findings demonstrated that queen bees had higher $\mathrm{Vg}$ and cholesterol levels in hemolymph than worker bees.

\subsection{Cholesterol levels, 20E levels, and Cyp314A1 messenger RNA expression}

Cholesterol in hemolymph can enter into trophocytes and oenocytes (Clark and Block, 1959). The mean cholesterol levels in the trophocytes and oenocytes of young and old worker bees and young and old queen bees were $39.33 \pm 3.07,16.83 \pm 1.68,97.98 \pm 14.06$, and $82.73 \pm 13.17 \mathrm{ng} \mu \mathrm{l}^{-1}$, respectively. Cholesterol levels significantly differed between young and old worker bees, between young worker bees and young and old queen bees, and between old worker bees and young and old queen bees $(n=5$, $P=0.008$; Fig. 2a).

Cholesterol can be used to synthesize 20E in the cholesterol-hydroxyecdysone pathway (Petryk et al. 2003; Yamazaki et al. 2011). We assayed 20E levels in the trophocytes and oenocytes of young and old worker bees and young and old queen bees. The mean 20E levels in young and old worker bees and young and old queen bees were 55.41 \pm 11.80 , $46.84 \pm 11.16,608.15 \pm 27.78$, and $809.21 \pm 90.95 \mathrm{ng} \mathrm{l}^{-1}$, respectively. $20 \mathrm{E}$ levels significantly differed between young worker bees and young and old queen bees and between old worker bees and young and old queen bees ( $n=5, P=0.008$; Fig. 2b). Queen bees have an average 14 times 20E levels than worker bees.

To further confirm ecdysteroid biosynthesis in the trophocytes and oenocytes of young and old worker bees and young and old queen bees, 

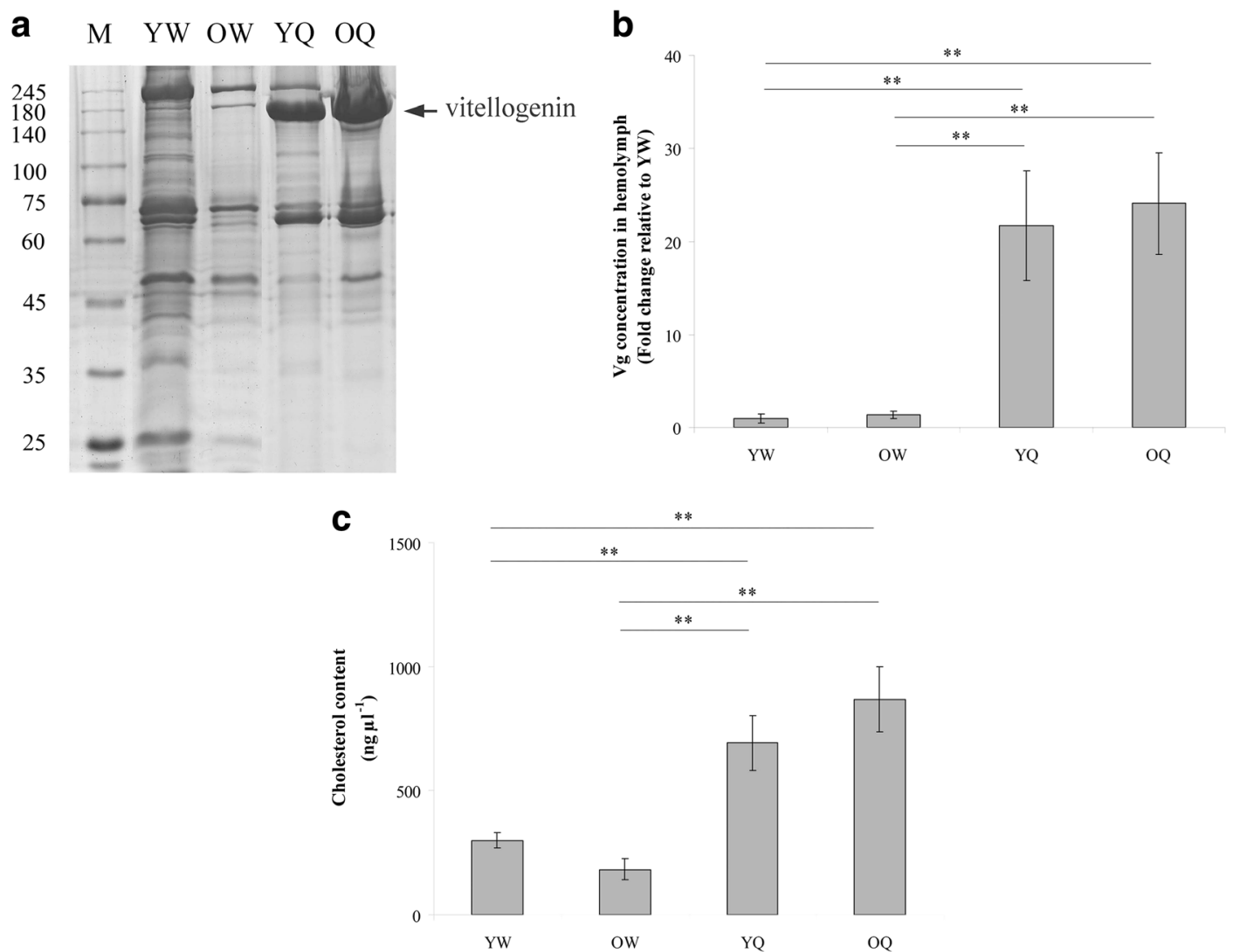

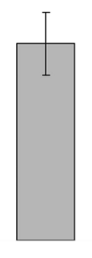

$\mathrm{YQ}$

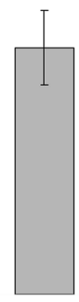

$\mathrm{OQ}$

Figure 1. Vg expression and cholesterol levels in the hemolymph of young and old worker bees and young and old queen bees. a Vg was analyzed using SDS-PAGE. b The results are normalized to the expression in young worker bees; they are presented as fold changes and represent the mean \pm standard error of the mean (SEM) $(n=5)$. c Cholesterol levels. The bars indicate the mean $\pm \operatorname{SEM~}(n=5)$. M, markers; YW, young worker bees; OW, old worker bees; YQ, young queen bees; $\mathrm{OQ}$, old queen bees. The asterisks indicate significant differences $(* * P<0.01$; MannWhitney $U$ test).

we assessed their Cyp314A1 messenger RNA (mRNA) expression levels. The fold changes in the mean Cyp314A1 mRNA expression levels in old worker bees, young queen bees, and old queen bees relative to young worker bees were $1.09 \pm 0.21,13.97 \pm 2.39$, and $14.06 \pm 4.22$, respectively. Cyp314A1 mRNA expression significantly differed between young worker bees and young and old queen bees and between old worker bees and young and old queen bees ( $n=5, P=0.008$; Fig. 2c). These findings indicated that the trophocytes and oenocytes of queen bees had higher cholesterol levels, $20 \mathrm{E}$ levels, and ecdysteroid biosynthesis than worker bees.

\subsection{EcR-A, EcR-B1, and USP mRNA expression}

To determine $20 \mathrm{E}$ receptor expression, we measured the mRNA expression of $E c R-A, E c R$ $B 1$, and USP in the trophocytes and oenocytes of young and old worker bees and young and old queen bees. The fold changes in the mean EcR-A mRNA expression levels in old worker bees, young queen bees, and old queen bees relative to young worker bees were $1.14 \pm 0.11,2.07 \pm 0.10$, and $2.21 \pm 0.25$, respectively. EcR-A mRNA expression significantly differed between young worker bees and young and old queen bees and between old worker bees and young and old 

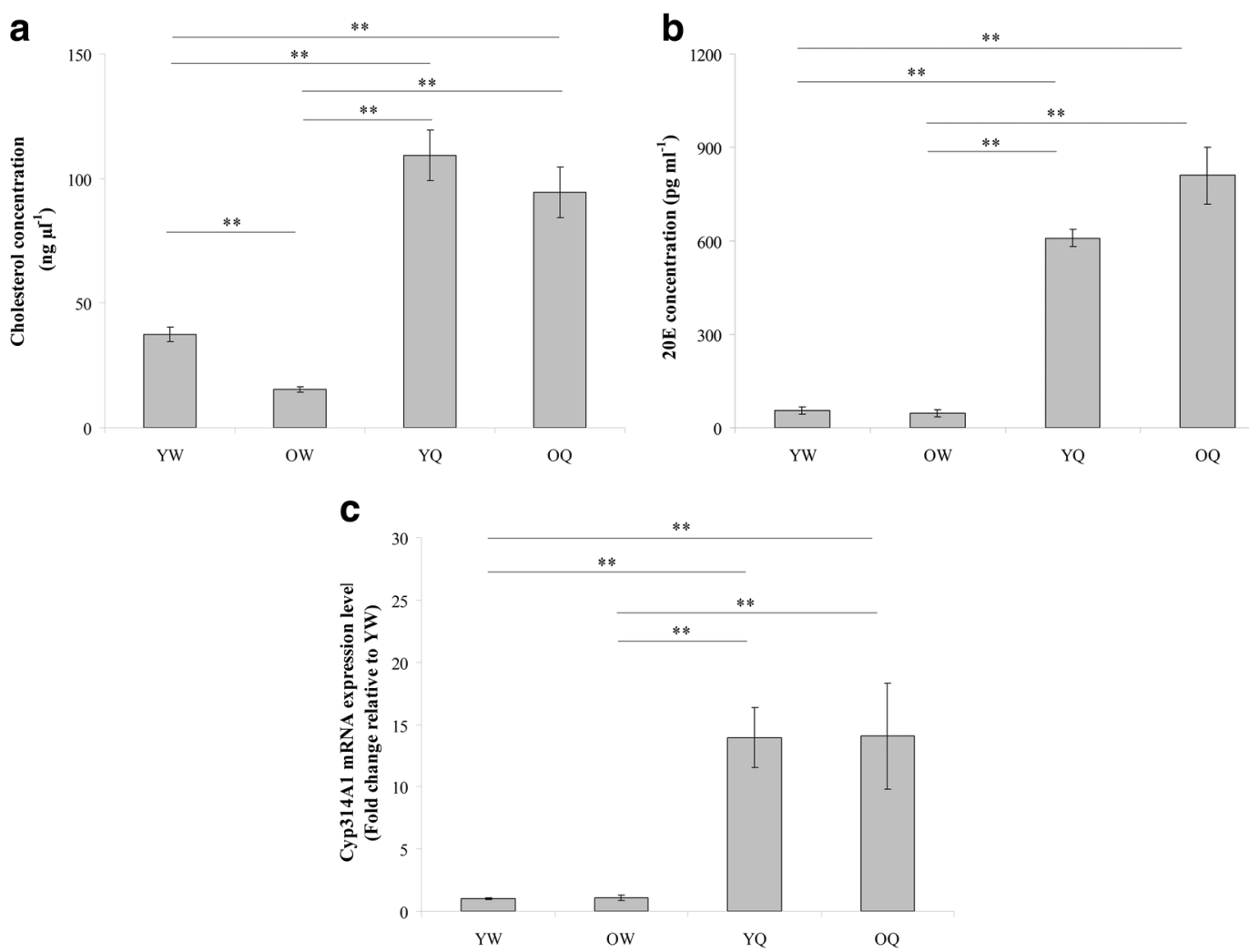

Figure 2. Cholesterol (a) and 20E (b) levels and Cyp314A1 mRNA expression (c) in the trophocytes and oenocytes of young and old worker bees and young and old queen bees. In $\mathbf{a}$ and $\mathbf{b}$, the bars indicate the mean $\pm \operatorname{SEM}(n=5)$. In $\mathbf{c}$, the results are normalized to the expression in young worker bees; they are presented as fold changes and represent the mean $\pm \operatorname{SEM}(n=5)$. YW, young worker bees; OW, old worker bees; YQ, young queen bees; $\mathrm{OQ}$, old queen bees. The asterisks indicate significant differences ( $* * P<0.01$; Mann-Whitney $U$ test).

queen bees ( $n=5, P=0.008$; Fig. 3a). The fold changes in the mean EcR-B1 mRNA expression levels in old worker bees, young queen bees, and old queen bees relative to young worker bees were $0.75 \pm 0.14,1.28 \pm 0.12$, and $1.17 \pm 0.08$, respectively. EcR-B1 mRNA expression significantly differed between young worker bees and young and old queen bees and between old worker bees and young and old queen bees $(n=5, P=0.008$; Fig. 3b). The fold changes in the mean USP mRNA expression levels in old worker bees, young queen bees, and old queen bees relative to young worker bees were $0.57 \pm 0.10,1.62 \pm 0.14$, and $1.81 \pm 0.18$, respectively. USP mRNA expression significantly differed between young and old worker bees, between young worker bees and young and old queen bees, and between old worker bees and young and old queen bees ( $n=5, P=0.008$; Fig. $3 \mathrm{c}$ ). These findings indicated that the trophocytes and oenocytes of queen bees had higher expression of EcR genes than worker bees.

\subsection{E74, E75, and BR-C mRNA expression}

To determine the expression of transcription factors of $\mathrm{Vg}$, we measured the mRNA expression of E74, E75, and BR-C in the trophocytes and oenocytes of young and old worker bees and young and old queen bees. The fold changes in the mean E74 mRNA expression levels in old worker bees, young queen bees, and old queen bees relative to young worker bees were $0.62 \pm 0.10,2.36 \pm 0.47$, and $2.15 \pm 0.28$, 
a

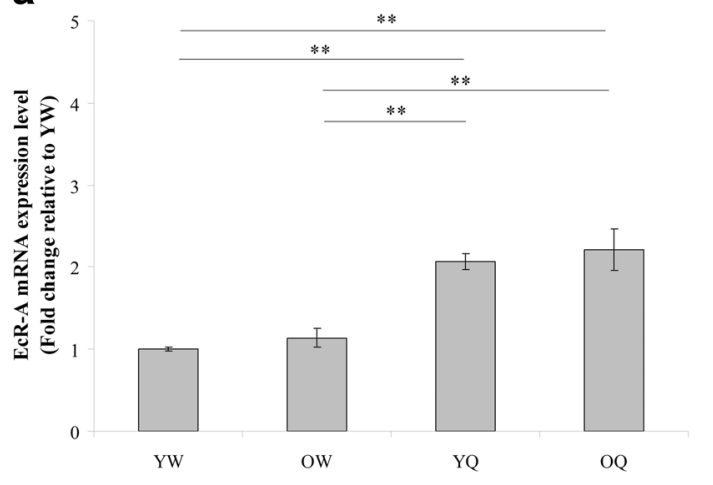

b

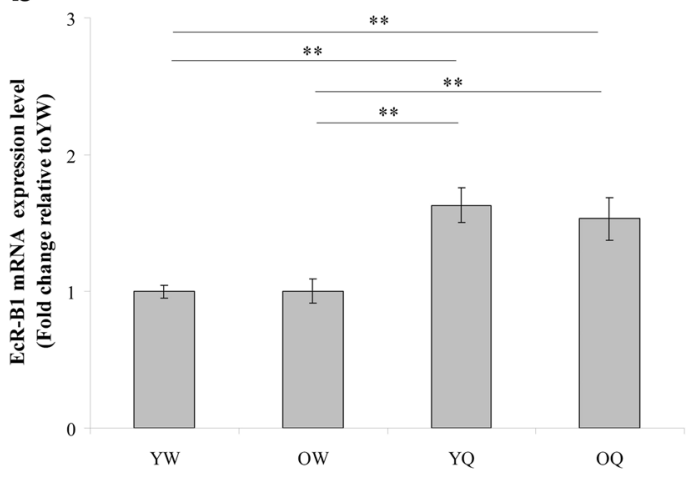

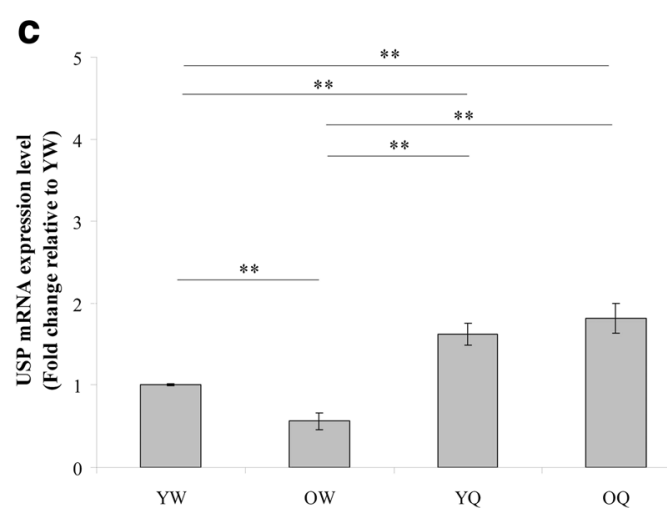

Figure 3. The mRNA expression of EcR-A (a),EcR-B1 (b), and USP (c) in the trophocytes and oenocytes of young and old worker bees and young and old queen bees. The results are normalized to the expression in young worker bees; they are presented as fold changes and represent the mean $\pm \operatorname{SEM}(n=5)$. YW, young worker bees; OW, old worker bees; YQ, young queen bees; OQ, old queen bees. The asterisks indicate significant differences $(* * P<0.01 ;$ Mann-Whitney $U$ test).

respectively. E74 mRNA expression significantly differed between young and old worker bees, between young worker bees and young and old queen bees, and between old worker bees and young and old queen bees $(n=5, P=0.008$; Fig. 4a). The fold changes in the mean E75 mRNA expression levels in old worker bees, young queen bees, and old queen bees relative to young worker bees were $1.20 \pm 0.35,2.39 \pm 0.36$, and $3.17 \pm 0.22$, respectively. E75 mRNA expression significantly differed between young worker bees and young and old queen bees and between old worker bees and young and old queen bees ( $n=5, P=0.008$; Fig. 4b). The fold changes in the mean BR-C mRNA expression levels in old worker bees, young queen bees, and old queen bees relative to young worker bees were
$1.21 \pm 0.18,5.91 \pm 0.74$, and $5.35 \pm 1.62$, respectively. BR-C mRNA expression significantly differed between young worker bees and young and old queen bees and between old worker bees and young and old queen bees $(n=5, P=0.008$; Fig. 4c). These findings indicated that the trophocytes and oenocytes of queen bees had higher expression of transcription factors of $\mathrm{Vg}$ than worker bees.

\subsection{Vg and VgR mRNA expression}

To understand $V g$ and $V g R$ expression, we measured $\mathrm{Vg}$ and $\mathrm{VgR}$ mRNA expression in the trophocytes and oenocytes of young and old worker bees and young and old queen bees. The fold changes in the mean Vg mRNA expression 
a

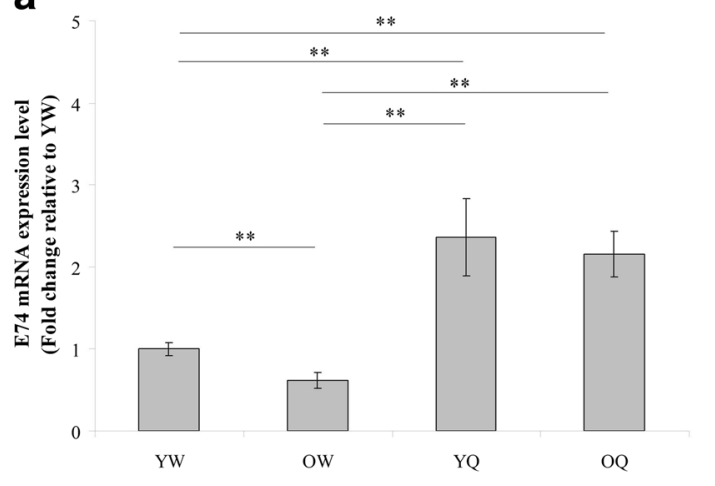

b

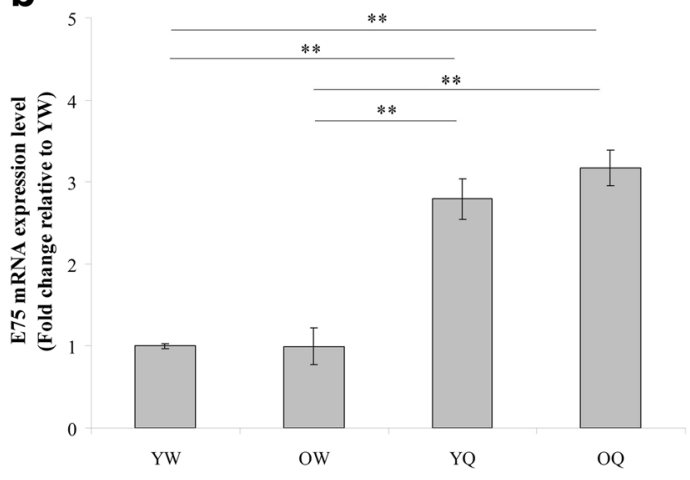

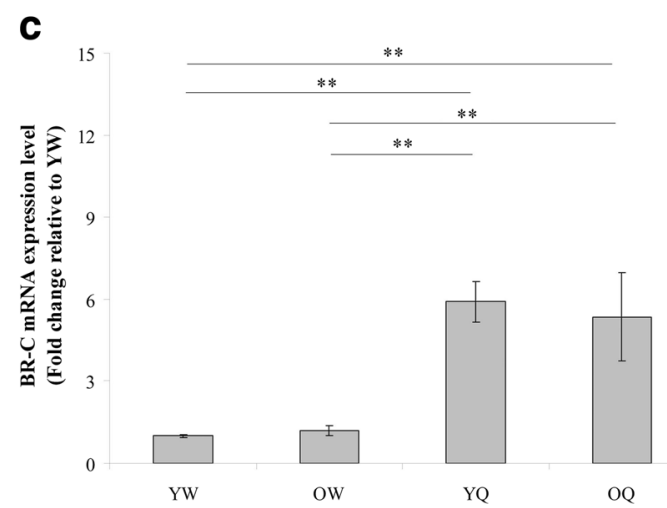

Figure 4. The mRNA expression of $E 74$ (a), $E 75$ (b) and $B R-C$ (c) in the trophocytes and oenocytes of young and old worker bees and young and old queen bees. The results are normalized to the expression in young worker bees; they are presented as fold changes and represent the mean $\pm \operatorname{SEM}(n=5)$. YW, young worker bees; OW, old worker bees; YQ, young queen bees; $\mathrm{OQ}$, old queen bees. The asterisks indicate significant differences $(* * P<0.01$; MannWhitney $U$ test).

levels in old worker bees, young queen bees, and old queen bees were $0.92 \pm 0.25,280.81 \pm 22.95$, and $233.37 \pm 62.31$, respectively. Vg mRNA expression significantly differed between young worker bees and young and old queen bees and between old worker bees and young and old queen bees ( $n=5, P=0.008$; Fig. 5a). Queen bees have an average 250 times Vg mRNA expression than worker bees. The fold changes in the mean VgR mRNA expression levels in old worker bees, young queen bees, and old queen bees relative to young worker bees were $0.99 \pm 0.22$, $11.09 \pm 2.51$, and $18.26 \pm 3.80$, respectively. VgR mRNA expression significantly differed between young worker bees and young and old queen bees and between old worker bees and young and old queen bees $(n=5, P=0.008$;
Fig. 5b). These findings indicated that the trophocytes and oenocytes of queen bees had higher $\mathrm{Vg}$ and $\mathrm{VgR}$ expression than worker bees.

\section{DISCUSSION}

We have explored the longevity mechanism of queen bees by assessing mitochondrial energy utilization, energy regulation activity, cellular degradation activity, and cellular metabolism in the trophocytes and oenocytes of worker and queen bees and have demonstrated that these cells exhibit aging phenotypes in worker bees but maintain longevity phenotypes in queen bees (Chuang and Hsu 2013; Hsu and Chuang 2014; Hsu et al. 2014; Lu et al. 2017; Hsu and $\mathrm{Hu}$ 2014; Hsu and Lu 2015; Hsu et al. 2016). To explore this mechanism further, 
a

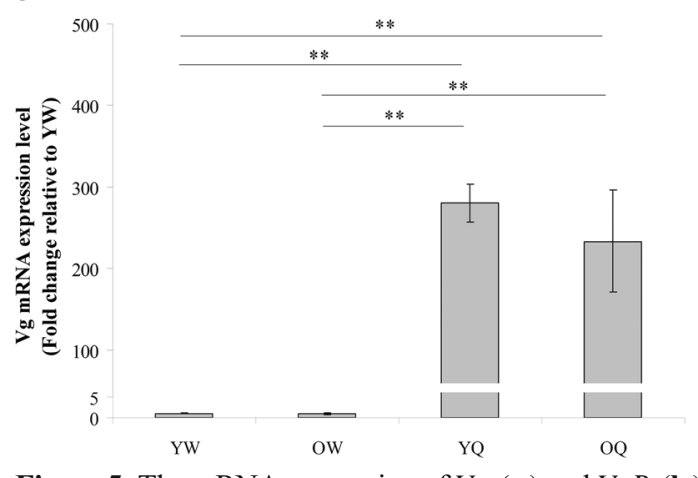

b

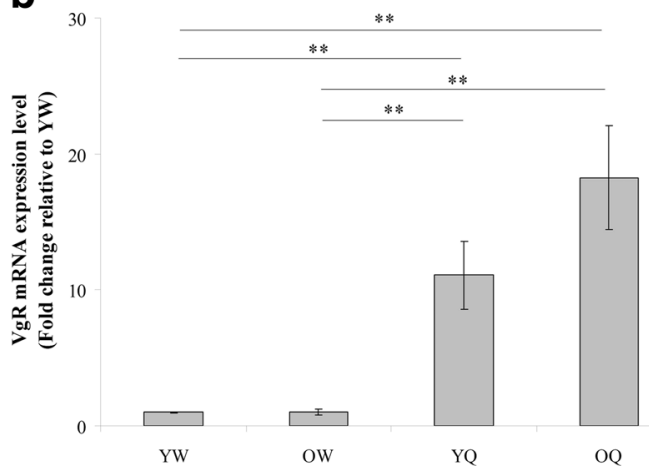

Figure 5. The mRNA expression of $V g(\mathbf{a})$ and $V g R(\mathbf{b})$ in the trophocytes and oenocytes of young and old worker bees and young and old queen bees. The results are normalized to the expression in young worker bees; they are presented as fold changes and represent the mean \pm SEM $(n=5)$. YW, young worker bees; OW, old worker bees; YQ, young queen bees; $O Q$, old queen bees. The asterisks indicate significant differences $(* * P<0.01$; MannWhitney $U$ test).

in this study, the molecules involved in the cholesterol-hydroxyecdysone-Vg pathway were assessed. The findings indicated that the trophocytes and oenocytes of queen bees have increased ecdysteroid and Vg biosynthesis compared with worker bees and parallel increases in the activation of the cholesterol-hydroxyecdysone- $\mathrm{Vg}$ pathway and the cellular function of queen bees, suggesting that the cholesterol-hydroxyecdysone$\mathrm{Vg}$ pathway is involved in the longevity of trophocytes and oenocytes of queen bees, which may be associated with the longevity of queen bees.

\section{1. $\mathrm{Vg}$ and cholesterol levels in hemolymph}

Trophocytes and oenocytes are immersed in hemolymph as honey bees have an open circulatory system. The cellular function of trophocytes and oenocytes is regulated by molecules in hemolymph. The hemolymph of queen bees has higher $\mathrm{Vg}$ levels than worker bees, indicating that $\mathrm{Vg}$ is not only associated with oogenesis but also contributed to cellular longevity. This inference is supported by previous studies showing that queen bees and long-lived winter worker bees have higher $\mathrm{Vg}$ expression (Seehuus et al. 2006; Aurori et al., 2014), knockdown of $\mathrm{Vg}$ decreases the lifespan of worker bees (Nelson et al. 2007), Vg is necessary for proper immune function (Amdam et al., 2004, 2005), Vg acts as an antioxidant in female honey bees (Seehuus et al. 2006; Corona et al. 2007), and Vg increases synthesis under Nosema ceranae infection (Lee and Nieh 2017). Vg may induce the capacity to respond to stress to increase the lifespan of queen bees.

$\mathrm{Vg}$ synthesis is regulated by $20 \mathrm{E}$, which is derived from cholesterol (Hansen et al. 2014; Yamazaki et al. 2011). Honey bees cannot synthesize cholesterol, which is derived from pollen in worker bees and from royal jelly in queen bees (Clark and Block, 1959). The hemolymph of queen bees has higher cholesterol levels than worker bees, indicating that queen bees have high cholesterol, which is used to synthesize 20E.

\subsection{Cholesterol levels, 20E levels, and Cyp314A1 mRNA expression}

The cholesterol of trophocytes and oenocytes is taken up from hemolymph. The cholesterol levels of trophocytes and oenocytes are proportional to those of hemolymph. The cholesterol of trophocytes and oenocytes can be converted to ecdysone, which can be further converted to $20 \mathrm{E}$ via Cyp314A1 20-hydroxylase in fruit flies (Petryk et al. 2003; Huang et al. 2008) and honey bees (Feldlaufer et al. 1986; Yamazaki et al. 2011). In this study, cholesterol, 20E, and Cyp314A1 mRNA expression levels in the trophocytes and oenocytes of queen bees were 
higher than those measured in worker bees, suggesting that ecdysteroid biosynthesis was increased in queen bees. This inference is consistent with a previous study showing that ecdysteroid hemolymph titers of queen bees are higher than those of laying worker bees and foragers (Robinson et al., 1991).

Cyp314A1 is expressed in the brains, ovaries, and fat bodies of worker honey bees (Yamazaki et al. 2011). The ovaries of egg-laying worker and queen honey bees express higher Cyp314A1 mRNA than those of nurse bees and foragers (Yamazaki et al. 2011). The egg-laying worker and queen honey bees also synthesize higher ecdysteroid than nurse bees and foragers (Robinson et al. 1991). In addition, queen bumble bees also express higher Cyp314A1 mRNA than worker bumble bees (Geva et al. 2005). These studies demonstrated that long-lived female bees highly express Cyp314A1 mRNA. This phenomenon indicated that $20 \mathrm{E}$ is associated not only with oogenesis but also with longevity. $20 \mathrm{E}$ effect on oogenesis and longevity may be mediated by $\mathrm{Vg}$ via the hydroxyecdysone- $\mathrm{Vg}$ pathway.

\subsection{EcR-A, EcR-B1, and USP mRNA expression}

The EcR-A/EcR-B1/USP complex functions as $20 \mathrm{E}$ cytoplasmic receptor in fruit flies (Yao et al. 1992; Talbot et al. 1993; Hill et al. 2013), mosquitos (Wang et al. 1998; Wang et al. 2002; Hansen et al. 2014), and honey bees (Takeuchi et al. 2007; Barchuk et al. 2008; Mello et al. 2014). EcR-A and EcR-BI are EcR subtypes in fruit flies (Talbot et al. 1993) and honey bees (Takeuchi et al. 2007). EcR-A is expressed in the brains and ovaries of honey bees (Takeuchi et al. 2007). This study demonstrated that $E c R-A, E c R$ $B 1$, and USP were also expressed in the trophocytes and oenocytes of female honey bees. Higher expression of EcR-A, EcR-B1, and USP mRNA in the trophocytes and oenocytes of queen bees indicated that ecdysone-triggered regulatory hierarchy was highly activated in queen bees than worker bees. These findings are consistent with the results of cholesterol, 20E, and Cyp314A1 in this study.

\subsection{E74, E75, and BR-C mRNA expression}

E74, E75, and BR-C are the transcription factors of $\mathrm{Vg}$ in fruit flies (Burtis et al. 1990; Segraves and Hogness 1990; Tzolovsky et al. 1999), mosquitos (Pierceall et al. 1999; Sun et al. 2002; Zhu et al. 2007), tobacco hornworms (Zhou et al. 1998), wax moths (Jindra et al. 1994), honey bees (Paul et al. 2005, 2006), and silkworm (Yang et al. 2014). In this study, E74, E75, and $B R-C$ were expressed at higher levels in the trophocytes and oenocytes of queen bees than worker bees, demonstrating that $E 74, E 75$, and $B R-C$ were expressed in the trophocytes and oenocytes of female honey bees. Higher expression of E74, E75, and BR-C mRNA in the trophocytes and oenocytes of queen bees confirmed that ecdysone-triggered regulatory hierarchies were activated in queen bees. These findings are consistent with the results of cholesterol, 20E, Cyp314A1, EcR-A, EcR-B1, and USP in this study.

\subsection{Vg and VgR mRNA expression}

$\mathrm{Vg}$ is expressed in the fat bodies of mosquitos (Deitsch et al. 1995), honey bees (Wyatt and Davey 1996), and silkworm (Yang et al. 2014). $V g$ and $V g R$ were expressed at higher levels in the trophocytes and oenocytes of queen bees than worker bees, indicating that queen bees synthesized greater amounts of $\mathrm{Vg}$ and $\mathrm{VgR}$. $\mathrm{Vg}$ mRNA expression in trophocytes and oenocytes is consistent with $\mathrm{Vg}$ expression in hemolymph. The high $V g$ and $V g R$ mRNA levels in trophocytes and oenocytes and high Vg levels in hemolymph suggest that the trophocytes and oenocytes of queen bees might perform the autocrine function through $\mathrm{Vg}$ binding to $\mathrm{VgR}$ to promote their longevity. $V g R$ has been found in the fat bodies, ovaries, head, hypopharyngeal gland, and midgut of honey bees (this article, Guidugli-Lazzarini et al. 2008). Vg may increase the cellular lifespan of $V g R$-expressing cells, leading to the longevity of queen bees.

$\mathrm{Vg}$ expression is promoted by the EcR/USP/ 20E and E74/E75/BR-C complexes in fruit flies (Hansen et al. 2014), mosquitos (Pierceall et al. 1999; Sun et al. 2002), and silkworm (Yang et al. 
2014). In this study, we demonstrated that Vg expression is correlated with the EcR/USP/20E and E74/E75/BR-C complex in the trophocytes and oenocytes of queen bees and that the cholesterol-hydroxyecdysone- $\mathrm{Vg}$ pathway is active in the trophocytes and oenocytes of queen bees, and this pathway is related to the longevity of trophocytes and oenocytes of queen bees.

\section{ACKNOWLEDGMENTS}

This work was supported by grants (CMRPD1E0022, CMRPD1G0081, CMRPD1E0023, CMRPD1G0581) from the Chang Gung Memorial Hospital, Linkou, Taiwan, and a grant (MOST1062311-B-182-003) from the Ministry of Science and Technology, Taiwan.

\section{AUTHOR CONTRIBUTIONS}

C.Y.L. and C.Y.H. designed the research; C.Y.L. performed the research; C.Y.L., P.J.H, and C.Y.H. analyzed the data; C.Y.H. wrote the paper.

La voie cholestérol-hydroxyecdysone-vitellogénine est impliquée dans la longévité des trophocytes et des oenocytes de reines (Apis mellifera)

Cholestérol / 20-hydroxyecdysone / vitellogénine / longévité / abeille.

Der Cholesterol-Hydroxyecdyson-VitellogeninStoffwechselweg beeinflusst die Lebensdauer von Trophozyten und Oenozyten der Bienenkönigin (Apis mellifera)

Cholesterol / 20-Hydroxyecdyson / Vitellogenin / Lebensdauer / Honigbiene.

\section{REFERENCES}

Amdam, G.V., Simoes, Z.L.P., Hagen, A., Norberg, K., Schroder, K., Mikkelsen, O., Kirkwood, T.B.L., Omholt, S.W. (2004) Hormonal control of yolk precursor vitellogenin regulates immune function and longevity in honeybees. Exp. Gerontol. 39, 767-773

Amdam, G.V., Aase, A.L., Seehuus, S.C., Fondrk, M.K., Norberg, K., Hartfelder, K. (2005) Social reversal of immunosenescence in honey bee workers. Exp. Gerontol. 40, 939-947
Aurori, C.M., Buttstedt, A., Dezmirean, D.S., Mărghitaş, L.A., Moritz, R.F.A., Erler, S. (2014) What is the main driver of ageing in long-lived winter honeybees: antioxidant enzymes, innate immunity, or vitellogenin? J. Gerontol. A Biol. Sci. Med. Sci. 69, 633-639

Barchuk, A.R., Figueiredo, V.L.C., Simões, Z.L.P. (2008) Downregulation of ultraspiracle gene expression delays pupal development in honeybees. J. Insect Physiol. 54, 1035-1040

Burtis, K.C., Thummel, C.S., Jones, C.W., Karim, F.D., Hogness, D.S. (1990) The Drosophila 74EF early puff contains E74, a complex ecdysone-inducible gene that encodes two ets-related proteins. Cell 61, 85-99

Chan, Q.W.T., Mutti, N.S., Foster, L.J., Kocher, S.D., Amdam, G.V., Florian, W. (2011) The worker honeybee fat body proteome is extensively remodeled preceding a major life-history transition. PLoS ONE 6, e24794

Chuang, Y.L., Hsu, C.Y. (2013) Changes in mitochondrial energy utilization in young and old worker honeybees (Apis mellifera). Age 35, 1867-1879

Clark, A.J., Block, K. (1959) The absence of sterol synthesis in insects. J. Biol. Chem. 234, 2578-2582

Corona, M., Velarde, R.A., Remolina, S., Moran-Lauter, A., Wang, Y., Hughes, K.A., Robinson, G.E. (2007) Vitellogenin, juvenile hormone, insulin signaling, and queen honey bee longevity. Proc. Natl. Acad. Sci. USA 104, 7128-7133

Deitsch, K.W., Chen, J.S., Raikhel, A.S. (1995) Indirect control of yolk protein genes by 20-hydroxyecdysone in the fat body of the mosquito, Aedes aegypti. Insect Biochem. Mol. Biol. 25, 449-454

Elsik, C.G., Worley, K.C., Bennett, A.K., Beye, M., Camara, F., et al. (2014) Finding the missing honey bee genes: lessons learned from a genome upgrade. BMC Genomics 15, 86

Feldlaufer, M.F., Herbert, E.W., Svoboda, J.A., Thompson, M.J. (1986) Biosynthesis of makisterone A and 20hydroxyecdysone from labeled sterols by the honey bee, Apis mellifera. Archiv. Insect Biochem. Physiol. 3, 415-421

Geva, S., Hartfelder, K., Bloch, G. (2005) Reproductive division of labor, dominance, and ecdysteroid levels in hemolymph and ovary of the bumble bee Bombus terrestris . J. Insect Physiol. 51, 811-823

Guidugli-Lazzarini, K.R., do Nascimento, A.M., Tanaka, É.D., Piulachs, M.D., Hartfelder, K., Bitondi, M.G., Paulino Simões, Z.L. (2008) Expression analysis of putative vitellogenin and lipophorin receptors in honey bee (Apis mellifera L.) queens and workers. J. Insect Physiol. 54, 1138-1147

Hansen, I.A., Attardo, G.M., Rodriguez, S.D., Drake, L.L. (2014) Four-way regulation of mosquito yolk protein precursor genes by juvenile hormone-, ecdysone-, nutrient-, and insulin-like peptide signaling pathways. Front. Physiol. 5, 103

Hill, R.J., Billas, I.M.L., Bonneton, F., Graham, L.D., Lawrence, M.C. (2013) Ecdysone receptors: from the Ashburner model to structural biology. Annu. Rev. Entomol. 58, 251-271 
Hsieh, Y.S., Hsu, C.Y. (2011a) Honeybee trophocytes and fat cells as target cells for cellular senescence studies. Exp. Gerontol. 46, 233-240

Hsieh, Y.S., Hsu, C.Y. (2011b) The changes of age-related molecules in the trophocytes and fat cells of queen honeybees (Apis mellifera). Apidologie 42, 728-739

Hsieh, Y.S., Hsu, C.Y. (2013) Oxidative stress and antioxidant enzyme activities in the trophocytes and fat cells of queen honeybees (Apis mellifera). Rejuvenation Res. 16, 295-303

Hsu, C.Y., Chan, Y.P. (2013) The use of honeybees reared in a thermostatic chamber for aging studies. Age 35, $149-158$

Hsu, C.Y., Chuang, Y.L. (2014) Changes in energyregulated molecules in the trophocytes and fat cells of young and old worker honeybees (Apis mellifera). J. Gerontol. A Biol. Sci. Med. Sci. 69, 955-964

Hsu, C.Y., Hu, T.H. (2014) Energy-regulated molecules maintain young status in the trophocytes and fat cells of old queen honeybees. Biogerontology 15, 389-400

Hsu, C.Y., Lu, C.Y. (2015) Mitochondrial energy utilization maintains young status in the trophocytes and oenocytes of old queen honeybees. Apidologie 46, 583-594

Hsu, C.Y., Chuang, Y.L., Chan, Y.P. (2014) Changes in cellular degradation activity in young and old worker honeybees (Apis mellifera). Exp. Gerontol. 50, 128136

Hsu, C.Y., Qiu, J.T., Chan, Y.P. (2016) Cellular degradation activity is maintained during aging in long-lived queen bees. Biogerontology 17, 829-840

Huang, X., Warren, J.T., Gilbert, L.I. (2008) New players in the regulation of ecdysone biosynthesis. J. Genet. Genomics 35, 1-10

Jindra, M., Sehnal, F., Riddiford, L.M. (1994) Isolation, characterization and developmental expression of the ecdysone-induced E75 gene of the wax moth Galleria mellonella . Eur. J. Biochem. 221 , 665-675

Keller, L., Jemielity, S. (2006) Social insects as a model to study the molecular basis of ageing. Exp. Gerontol. 41, 553-556

Kuterbach, D.A., Walcott, B. (1986) Iron-containing cells in the honey-bee (Apis mellifera). I. Adult morphology and physiology. J. Exp. Biol. 126, 375-387

Lee R. B, Nieh J.C. (2017) Larval honey bees infected with Nosema ceranae have increased vitellogenin titers as young adults. Sci. Rep. 7, 14144.

Lourenco, A.P., Mackert, A., Cristino, A.D., Simoes, Z.L.P. (2008) Validation of reference genes for gene expression studies in the honey bee, Apis mellifera, by quantitative real-time RT-PCR. Apidologie 39, 372-385

Lu, C.Y., Chuang, Y.L., Hsu, C.Y. (2017) Aging results in a decline in cellular energy metabolism in the trophocytes and oenocytes of worker honeybees (Apis mellifera ). Apidologie 48, 761-775

Mello, T.R.P., Aleixo, A.C., Pinheiro, D.G., Nunes, F.M.F., Bitondi, M.M.G., Hartfelder, K., Barchuk, A.R., Simões, Z.L. (2014) Developmental regulation of ecdysone receptor $(\mathrm{EcR})$ and EcR-controlled gene expression during pharate-adult development of honeybees (Apis mellifera). Front. Genet. 5, 445

Nelson, C.M., Ihle, K.E., Fondrk, M.K., Page, R.E. Jr, Amdam, G.V. (2007) The gene vitellogenin has multiple coordinating effects on social organization. PLoS Biol. 5, e62

Nilsen, K.A., Ihle, K.E., Frederick, K., Fondrk, M.K., Smedal, B., Hartfelder, K., Amdam, G.V. (2011) Insulin-like peptide genes in honey bee fat body respond differently to manipulation of social behavioral physiology. J. Exp. Biol. 214, 1488-1497

Paes-de-Oliveira, V.T., Cruz-Landim, C. (2003) Size of fat body trophocytes and the ovarian development in workers and queens of Melipona quadrifasciata anthidioides. Sociobiology 4, 701-709

Paul, R.K., Takeuchi, H., Matsuo, Y., Kubo, T. (2005) Gene expression of ecdysteroid-regulated gene E74 of the honeybee in ovary and brain. Insect Mol. Biol. 14, 9-15

Paul, R.K., Takeuchi, H., Kubo, T. (2006) Expression of two ecdysteroid-regulated genes, broad-complex and E75, in the brain and ovary of the honeybee (Apis mellifera L.). Zool. Sci. 23, 1085-1092

Petryk, A., Warren, J.T., Marques, G., Jarcho, M.P., Gilbert, L.I., Kahler, J., Parvy, J.P., Li, Y., Dauphin-Villemant, C., O'Connor, M.B. (2003) Shade is the Drosophila P450 enzyme that mediates the hydroxylation of ecdysone to the steroid insect molting hormone 20hydroxyecdysone. Proc. Natl. Acad. Sci. USA 100 , 13773-13778

Pierceall, W.E., Li, C., Biran, A., Miura, K., Raikhel, A.S., Segraves, W.A. (1999) E75 expression in mosquito ovary and fat body suggests reiterative use of ecdysone-regulated hierarchies in development and reproduction. Mol. Cell. Endocrinol. 150, 73-89

Remolina, S.C., Hughes, K.A. (2008) Evolution and mechanisms of long life and high fertility in queen honey bees. Age 30, 177-185

Robinson, G.E., Strambi, C., Strambi, A., Feldlaufer, M.F. (1991) Comparison of juvenile hormone and ecdysteroid titres in adult worker and queen honey bees. J. Insect Physiol. 37, 929-935

Sappington, T.W., Raikhel, A.S. (1995) Receptor-mediated endocytosis of yolk proteins by insect oocytes. In Recent advances in insect biochemistry and molecular biology, eds Ohnishi E, Sonobe H, Takahashi SY. Nagoya University Press, Nagoya, 235-257

Seehuus, S.-C., Norberg, K., Gimsa, U., Krekling, T., Amdam, G.V. (2006) Reproductive protein protects functionally sterile honey bee workers from oxidative stress. Proc. Natl. Acad. Sci. USA 103, 962-967

Seehuus, S.-C., Taylor, S., Petersen, K., Aamodt, R.M. (2013) Somatic maintenance resources in the honeybee worker fat body are distributed to withstand the most life-threatening challenges at each life stage. PLoS ONE 8, e69870

Segraves, W.A., Hogness, D.S. (1990) The E75 ecdysone inducible gene responsible for the $75 \mathrm{~B}$ early puff in Drosophila encodes two new members of the steroid receptor superfamily. Genes Dev. 4, 204-219 
Sun, G., Zhu, J., Li, C., Tu, Z., Raikhel, A.S. (2002) Two isoforms of the early E74 gene, an Ets transcription factor homologue, are implicated in the ecdysteroid hierarchy governing vitellogenesis of the mosquito, Aedes aegypti. Mol. Cell. Endocrinol. 190 , 147-157

Takeuchi, H., Paul, R.K., Matsuzaka, E., Kubo, T. (2007) EcR-A expression in the brain and ovary of the honeybee (Apis mellifera L.). Zool. Sci. 24, 596-603

Talbot, W.S., Swyryd, E.A., Hogness, D.S. (1993) Drosophila tissue with different metamorphic responses to ecdysone express different ecdysone receptor isoforms. Cell 73, 1323-1337

The Honeybee Genome Sequencing Consortium (2006) Insights into social insects from the genome of the honeybee Apis mellifera. Nature 443, 931-949

Tzolovsky, G., Deng, W.M., Schlitt, T., Bownes, M. (1999) The function of the broad-complex during Drosophila melanogaster oogenesis. Genetics 153, 1371-1383

Wang, S.F., Miura, K., Miksicek, R.J., Segraves, W.A., Raikhel, A.S. (1998) DNA binding and transactivation characteristics of the mosquito ecdysone receptorUltraspiracle complex. J. Biol. Chem. 273, 2753127540

Wang, S.F., Li, C., Sun, G., Zhu, J., Raikhel, A.S. (2002) Differential expression and regulation by 20 hydroxyecdysone of mosquito ecdysteroid receptor isoforms A and B. Mol. Cell. Endocrinol. 196, 29-42

Wang, Y., Jorda, M., Jones, P.L., Maleszka, R., Ling, X., Robertson, H.M., Mizzen, C.A., Peinado, M.A., Robinson, G.E. (2006) Functional CpG methylation system in a social insect. Science 314, 645-647
Wheeler, D.E., Kawooya, J.K. (1990) Purification and characterization of honey bee vitellogenin. Arch. Insect Biochem. Physiol. 14, 253-267

Wyatt, G.R., Davey, K.G. (1996) Cellular and molecular actions of juvenile hormone. II. Roles of juvenile hormone in adult insects. Adv. Insect Physiol. 26, 1-155

Yamazaki, Y., Kiuchi, M., Takeuchi, H., Kubo, T. (2011) Ecdysteroid biosynthesis in workers of the European honeybee Apis mellifera L. Insect Biochem. Mol. Biol. 41, 283-293

Yang, C., Lin, Y., Liu, H., Shen, G. (2014) The broad complex isoform 2 (BrC-Z2) transcriptional factor plays a critical role in vitellogenin transcription in the silkworm Bombyx mori. Biochim. Biophys. Acta $1840,2674-2684$

Yao, T.P., Sagraves, W.A., McKeown, M., Evans, R.M. (1992) Drosophila ultra-spiracle modulates ecdysone receptor function via heterodimer formation. Cell $\mathbf{7 1}$, 63-72

Zhou, B., Hiruma, K., Shinoda, T., Riddiford, L.M. (1998) Juvenile hormone prevents ecdysteroid-induced expression of broad complex RNAs in the epidermis of the tobacco hornworm Manduca sexta. Dev. Biol. 203, 233-244

Zhu, J., Chen, L., Raikhel, A.S. (2007) Distinct roles of Broad isoforms in regulation of the 20 hydroxyecdysone effector gene, vitellogenin, in the mosquito Aedes aegypti. Mol. Cell. Endocrinol. 267, 97-105 